\title{
Effects of Sugar Substitution with "Stevianna" on the Sensory Characteristics of Muffins
}

\author{
Jingrong Gao, Margaret A. Brennan, Susan L. Mason, and Charles S. Brennan \\ Department of Wine, Food and Molecular Biosciences, Lincoln University, P.O. Box 85084 Lincoln, Canterbury 7647, New Zealand
}

Correspondence should be addressed to Susan L. Mason; sue.mason@lincoln.ac.nz

Received 8 September 2016; Revised 16 December 2016; Accepted 29 December 2016; Published 22 February 2017

Academic Editor: Maria Rosaria Corbo

Copyright (C) 2017 Jingrong Gao et al. This is an open access article distributed under the Creative Commons Attribution License, which permits unrestricted use, distribution, and reproduction in any medium, provided the original work is properly cited.

Sugar is a main ingredient of muffins and other baked products, so removal or reduction of sucrose negatively affects product appearance, texture, and mouthfeel. The aim of this study was to investigate the colour, textural properties, and sensory characteristics of sugar replaced muffins made using stevianna in combination with cocoa powder and/or vanilla. Optimal results were obtained with $50 \%$ stevianna, leading to muffins similar to the control products and having a high level of acceptance in sensory evaluation. Sugar-free muffins (100\% stevianna) were harder in texture and more compact in crumb compared to the control. Results from sensory evaluation also illustrated that $100 \%$ stevianna addition led to muffins with poorer acceptance, harder texture, and a drier mouthfeel when compared against the control. This study also investigated the use of cocoa powder and/or vanilla to mask the stevianna bitterness in terms of aftertaste.

\section{Introduction}

Consumers are becoming increasingly aware of the nutritional quality of food products and the link with health. The prevalence of obesity and overweight has increased dramatically with suggestions that in Europe the prevalence of obesity had risen threefold since the 1980s [1]. As a result, the food industry has focused on reducing caloric content by production of sugar-free foods. However, continued consumption of low-calorie foods is difficult to achieve as these products are often evaluated as having poor organoleptic qualities [2]. Sucrose in bakery products makes a major contribution to providing sweetness, controlling moisture retention, influencing air incorporation, stabilising air bubbles, and limiting the swelling of starch during baking, all of which help to create a finer texture [3]. There are many reports that show reduced sucrose products to be less acceptable than their full-sucrose counterparts [4-7]. The structural and sensory properties of the muffin system have been shown to be influenced by the reduction in sucrose levels [8]. Therefore, intense sweeteners cannot solely replace sugar and the food industry is facing the challenge of developing new bakery products where reducing sucrose content of baked goods would reduce calories while maintaining the sensory quality and the acceptability of the product. It is important to find alternative sugar replacers for traditional sugars in order to improve the quality of low-sugar muffins.

Stevia is the generic term used for food ingredients that are a group of intensely sweet compounds extracted and purified from the herb Stevia rebaudiana (Bertoni). A more precise term for these compounds is steviol glycoside. The main sweetening components in Stevia leaves are stevioside and rebaudioside A [9]. Rebaudioside A is a high-intensity sweetener with a relative sweetness 350-450 times that of sucrose; however the bitterness that presents as an aftertaste affects the sensory quality of the final product [10]. Stevia has been indicated for use as a sweetener by diabetics [11]. Safety studies have shown no side effects and stevia has been approved as a safe ingredient by JECFA, WHO, and FDA, with FSANZ (Food Safety Australia and New Zealand) setting an acceptable daily intake (ADI) at 0$4 \mathrm{mg}$ steviol equivalents [12]. Stevianna combines the main sugar substitute of rebaudioside A (98\% steviol glycoside; 1\%) with erythritol (99\%) to provide one time sweetness of sucrose (product code ST001_SE supplied by Stevianna NZ). Erythritol, a four-carbon sugar alcohol with sweetness intensity varying from $60 \%$ to $80 \%$ that of sucrose [13], is a useful functional food ingredient because it has a high 
digestive tolerance (daily at doses of $1 \mathrm{~g} / \mathrm{kg}$ body weight), is noncaloric, noncariogenic, and nonglycaemic, and has been reported to have antioxidant properties [14]. It is the only sugar alcohol produced commercially by fermentation of wheat or corn starch [10]. Erythritol has been classified as nontoxic from acute and subchronic studies in animals [15], and consequently the FDA has declared erythritol generally recognized as safe (GRAS) for use in foods.

In bakery products, using stevia to replace sucrose causes an increase in hardness, cohesiveness, and toughness of cake structure and has therefore been evaluated as being suitable for high sweetness intensity but it does not support texture characteristics [4]. Similarly, Edelstein et al. [6] found that compared with other artificial sweeteners stevia produced least desirable cupcakes when replacing sucrose on a w/w basis. They also reported that stevia had a distinct bitterness in flavour or strong aftertaste that could limit its application in foods. However, adding hydrocolloids, sugar alcohols, or plant fibres may have a positive effect on the loss of volume and bulk when the amount of sucrose is reduced in bakery products [10]. Lin et al. [16] reported that use of erythritol as the bulking agent for sugar replacement in chiffon cakes resulted in desirable physical quality characteristics but indicated that if $100 \%$ sucrose was replaced by erythritol there was a significant loss of sweetness.

Zahn et al. [17] used a combination of inulin with rebaudioside $\mathrm{A}$ to make reduced sugar muffins and illustrated that the resulting products had characteristics close to a reference muffin formulation as determined by sensory evaluation. Baeva et al. [18] also demonstrated that complete sucrose substitution could be achieved by replacing sugar with aspartame and bulking agents (sorbitol, wheat starch, and wheat germ) in sponge cakes for diabetics. Additionally replacement of $50 \%$ sucrose by a mixture of erythritol and sucralose in reduced fat chiffon cakes resulted in no negative influences on the sensory and physical quality characteristics [19]. It is well known that consumers are highly sensitive to even small variations in sweetness [5]. Martínez-Cervera et al. [8] studied the effect of polyols on the acceptability of muffins and showed no differences for sensory acceptance. Similar results have been obtained in studies using sweeteners in cakes, where overall acceptance followed closely the scores of textural properties and taste [7]. Manisha et al. [20] conducted research using a mixture of stevioside and liquid sorbitol in cakes illustrating that hedonic response profiles ascended gradually with increasing sucrose replacement content.

Our previous work [21] illustrated the effect of sucrose replacement by stevianna in muffins and concluded that replacement of up to $50 \%$ of sugar resulted in products with textural qualities similar to full-sugar muffins. This manuscript focuses on the effect of sugar replacement by two levels of stevianna in muffin products with the addition of cocoa powder and/or vanilla. The usefulness of cocoa powder and/or vanilla to mask any potential aftertaste that may result from the incorporation of stevianna was evaluated. The formulated muffins were evaluated for their physical properties (colour analysis and textural properties) via instrumental analysis. A sensory panel was also used to compare the effect of sugar replacement on the product's sensory properties. All muffins were compared to a control muffin formulation with no added stevianna, cocoa powder, or vanilla.

\section{Materials and Methods}

2.1. Raw Materials. Muffins were prepared containing 0\%, $50 \%$, and $100 \%$ stevianna (product code ST001_SE; Stevianna, New Zealand) as a replacement for sucrose. Stevianna utilizes one percent Reb-A 98\% steviol glycoside as the main sugar substitute along with erythritol (99\%). Wheat flour (Medal Premium Baker Flour, Champion, New Zealand), white sugar (Chelsea, New Zealand), baking powder (Edmonds, New Zealand), iodised table salt (Cerebos, New Zealand), skim milk powder (0.1 fat, Pams, New Zealand), 100\% cocoa powder (Cadbury, New Zealand), vanilla (Hansells, Australia), canola oil (Pams, New Zealand), and fresh eggs were purchased from a local supermarket and tap water was used.

2.2. Muffin Preparation. Muffins were prepared based on the recipe previously described [21] using ingredients shown in Table 1. Baked muffins were cooled at room temperature for $1 \mathrm{~h}$, then packed in plastic resealable bags, and stored at $4^{\circ} \mathrm{C}$ until physical analysis. Muffins for sensory evaluation were prepared on the morning of each trial.

2.3. Physical Measurement on Muffins. Firmness and springiness of the muffin samples were determined with a TA.XT.plus Texture Analyzer (Stable Microsystems, Godalming, UK) using the Texture Expert software provided. Measurements were conducted using a $50 \mathrm{~kg}$ load cell and a $75 \mathrm{~mm}$ cylindrical probe. The texture parameters were determined with a test speed of $1.0 \mathrm{~mm} / \mathrm{s}$ and the application of strain of $25 \%$ of the original height. The compression test was obtained from the two primary textural parameters from the curves, as calculated by the Texture Expert software. The test was performed on four muffins from each recipe.

The colours of inside (crumb) and top of muffin (crust) samples were analysed using a Tristimulus Colour Analyzer (Minolta Chroma Meter CR200, Minolta Camera Co., Japan). The instrument was equipped with a CR200 measuring head connected to a microcomputer and was calibrated using the standard white tile $\left(L^{*}-98.03, a^{*}--0.23\right.$, and $b^{*}-$ $0.25)$. Measurements were conducted in triplicate, and the results are expressed as mean for $L^{*}, a^{*}$, and $b^{*}$ values of the illuminant $\mathrm{C}$ system (CIE, standard, $6774 \mathrm{~K}$ ). In addition, results are expressed as total colour difference $\left(\Delta E^{*}\right)$ between control sample and sugar-reduced products according to the following equation [22]:

$$
\Delta E^{*}=\sqrt{\Delta L^{* 2}+\Delta a^{* 2}+\Delta b^{* 2}},
$$

where $L^{*}$ is brightness and ranges from 0 (black) to 100 (white), $a^{*}$ is redness from +100 (redness) to -100 (greenness), and $b^{*}$ is the yellowness from +100 (yellowness) to -100 (blueness).

The perception of the colour difference $\Delta E^{*}$ has been observed to vary according to the colour and the sensitivity 


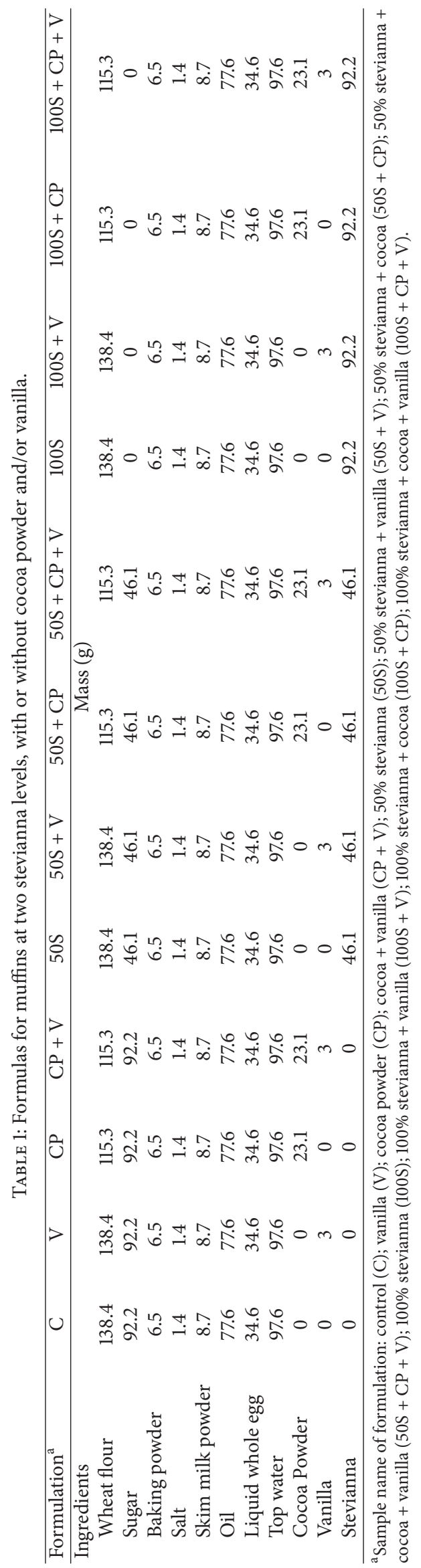


TABLE 2: Description of the scale anchors used from left side to right side.

\begin{tabular}{lc}
\hline Variables category & Scale anchors \\
\hline Visually & Not at all appealing to extremely appealing \\
Colour & Extremely light to extremely dark \\
Texture & Extremely soft to extremely hard \\
Mouthfeel & Extremely moist to extremely dry \\
Sweetness & Not sweet at all to extremely sweet \\
Overall liking & Dislike extremely to like extremely \\
\hline
\end{tabular}

of the human eye [23]. When $\Delta E^{*}$ is less than 1 no colour difference is obvious to the human eye; $1<\Delta E^{*}<3$ minor colour differences could be appreciated by the human eye depending on the hue, and when $\Delta E^{*}>3$ colour differences are obvious for the human eye [24].

The three-dimensional $L^{*}, a^{*}$, and $b^{*}$ colour are also expressed as a browning index (BI), as shown in the equation below [22]:

$$
\mathrm{BI}=\frac{100(X-0.31)}{0.172},
$$

where $X=a^{*}+1.75 L^{*} /\left(5.645 L^{*}+a^{*}-3.012 b^{*}\right)$.

2.4. Sensory Evaluation. Sensory evaluation was conducted in the food sensory suite at Lincoln University. The trial was approved by the Lincoln University human ethic committee (2015-38). Panellists were recruited by email and were not informed of the treatments. Potential panellists who had a history of serious anaphylactic reaction to any food or a history of significant bowel disease (including Crohn's; ulcerative colitis; Coeliac's disease) were excluded. The experiment involved three sessions which were conducted over 3 weeks. A consumer panel of 40 untrained panellists (staff and students of Lincoln University) completed the sensory evaluation study. In this study, muffins were cut into quarters, revealing both crust and crumb. Panellists received four samples of muffins at the first tasting session, and 5 samples were provided at each of the following two sessions. All samples were coded with random 3-digit numbers and were served simultaneously on white plastic trays.

Line scales of $15 \mathrm{~cm}$ were used to record panellists' opinions. Line scales are more common than category scales in contemporary sensory studies. Their advantages are that they avoid decisions by the experimenter about category labels and spacing and that they are less constraining in actual use by the panellists. Panellists indicate their judgments by placing a mark at any point on the line and so may indicate minor differences between products which may have been grouped together under a category scale [25]. The detailed information of scale anchors is shown in Table 2. The response categories were appearance, colour, texture, mouthfeel, sweetness, and overall liking of the muffin. Panellists were asked directly about the presence of an aftertaste and if present to describe it.

\subsection{Statistical Analysis}

2.5.1. Data Analysis of Physical Measurements. All physical results were analysed using Minitab 17 in a one-way ANOVA model. Significance was determined using Tukey's comparison test $(P<0.05)$.

2.5.2. Data Analysis of Sensory Evaluation. For all products, participant ratings on the labelled $15 \mathrm{~cm}$ line scale were measured geometrically to produce factor values $(\mathrm{cm})$. In the data processing procedure, the control value was subtracted from the sample value for each parameter for each participant before the data was analysed. The control sample values were used as the relative value (0) for each parameter in this study, as the control muffin was presented at each session with the rest of the samples and was evaluated in random order among panellists. This gives a positive or negative value which can be interpreted as being "more" or "less" than the control as shown in Table 3. Thus, figures obtained in the present work are relative values.

Data from assessment of appearance, colour, texture, mouthfeel, sweetness, and overall liking were evaluated separately by analysis of variance (one-way ANOVA) using Minitab 17. A value of $P<0.05$ was selected for statistical significance using Tukey's comparison test. Responses to a question about presence of aftertaste were coded as " 0 " for no-aftertaste and " 1 " for an aftertaste. The aftertaste data was evaluated using nominal logistic regression of Minitab 17.

In order to analyse the relationship between different products types based on the individual response categories, principle component analysis (PCA) was performed on individual data using Minitab 17. Briefly, this method attempted to explain the relationship between variables and each major axis produced is a result of their joint contribution. In order to produce meaningful results, the first two or three axes must account for a considerable percentage of the total variance [26].

\section{Results and Discussion}

3.1. Colour Analysis of the Muffins. The colour of muffins is an important factor which affects the acceptability of the product and is directly influenced by the raw materials used in the formulation. Figure 1 is a photo of samples of the muffins and demonstrates the colour changes with each treatment. Figures 2 and 3 show $L^{*}, a^{*}$, and $b^{*}$ : the lightness, the redness, and the yellowness, respectively. The samples were divided into two groups: without cocoa powder and with cocoa powder (Table 4).

3.1.1. Crust Colour. In the group without cocoa powder, $L^{*}$ values of muffins were not affected by the replacement of sucrose with stevianna. Samples containing stevianna had higher $a^{*}$ values (redness) when compared to the control while samples with $100 \%$ stevianna $(100 \mathrm{~S}$ and $100 \mathrm{~S}+\mathrm{V})$ had significantly lower $(P<0.05)$ mean value for the yellowness $\left(b^{*}\right)$ than the controls. The changes in $a^{*}$ and $b^{*}$ values may be because stevianna is thermos stable and contains nonreducing substances, does not react with amino acids by Maillard reaction [6], and has limited caramelization. This is 
TABLE 3: Description of calculated factor values.

\begin{tabular}{lccc}
\hline Variables category & & Factor values after calculation* & \\
& Positive $(+)$ & 0 & Negative $(-)$ \\
\hline Visually & Better than control & Same as Control & Worse than control \\
Colour & Darker than control & Same as Control & Sighter than control \\
Texture & Harder than control & Same as Control than control \\
Mouthfeel & Dryer than control & Same as Control & Moister than control \\
Sweetness & Sweeter than control & Same as Control & Less sweet than control \\
Overall liking & Better than control & Same as Control & Worse than control \\
\hline
\end{tabular}

${ }^{*}$ There values are relative to control muffin.

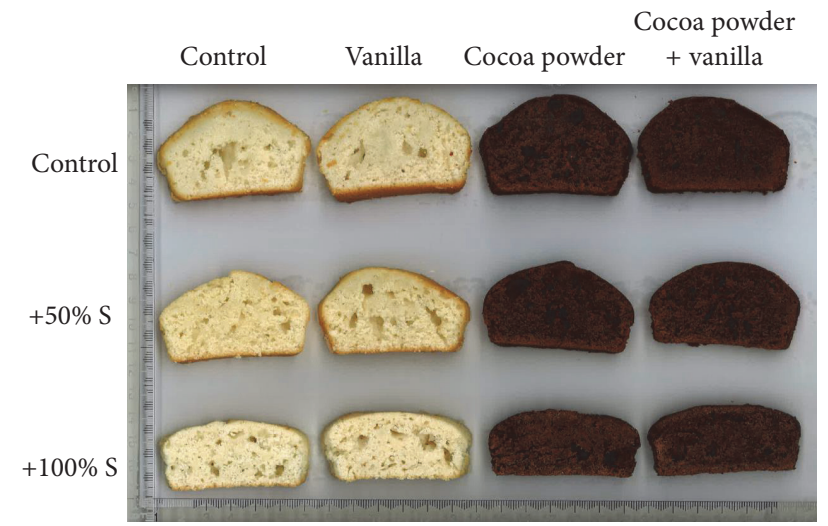

FIGURE 1: Effect of stevianna without/with cocoa powder and/or vanilla on the crumb colour of muffin. muffins are, from left to right and top to bottom, control $(\mathrm{C})$; vanilla $(\mathrm{V})$; cocoa powder $(\mathrm{CP})$; cocoa + vanilla $(\mathrm{CP}+\mathrm{V}) ; 50 \%$ stevianna $(50 \mathrm{~S}) ; 50 \%$ stevianna + vanilla $(50 \mathrm{~S}+\mathrm{V}) ; 50 \%$ stevianna + cocoa $(50 \mathrm{~S}+\mathrm{CP}) ; 50 \%$ stevianna + cocoa + vanilla $(50 \mathrm{~S}+\mathrm{CP}+\mathrm{V}) ; 100 \%$ stevianna $(100 \mathrm{~S}) ; 100 \%$ stevianna + vanilla $(100 \mathrm{~S}+\mathrm{V}) ; 100 \%$ stevianna + cocoa $(100 \mathrm{~S}+\mathrm{CP})$; $100 \%$ stevianna + cocoa + vanilla $(100 \mathrm{~S}+\mathrm{CP}+\mathrm{V})$.

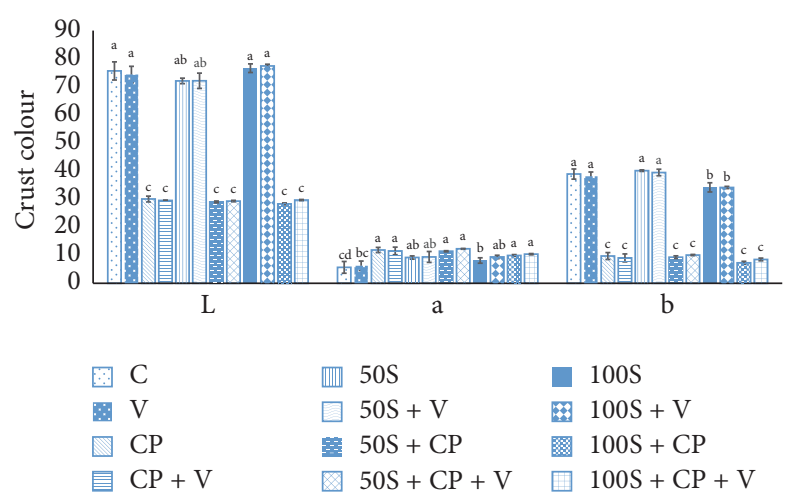

FIGURE 2: Effect of stevianna without/with cocoa powder and/or vanilla on the crust colour of muffin. Control (C); vanilla (V); cocoa powder $(\mathrm{CP})$; cocoa + vanilla $(\mathrm{CP}+\mathrm{V}) ; 50 \%$ stevianna $(50 \mathrm{~S}) ; 50 \%$ stevianna + vanilla $(50 \mathrm{~S}+\mathrm{V}) ; 50 \%$ stevianna + cocoa $(50 \mathrm{~S}+\mathrm{CP})$; $50 \%$ stevianna + cocoa + vanilla $(50 \mathrm{~S}+\mathrm{CP}+\mathrm{V}) ; 100 \%$ stevianna $(100 S) ; 100 \%$ stevianna + vanilla $(100 \mathrm{~S}+\mathrm{V}) ; 100 \%$ stevianna + cocoa $(100 \mathrm{~S}+\mathrm{CP}) ; 100 \%$ stevianna + cocoa + vanilla $(100 \mathrm{~S}+\mathrm{CP}+\mathrm{V})$.

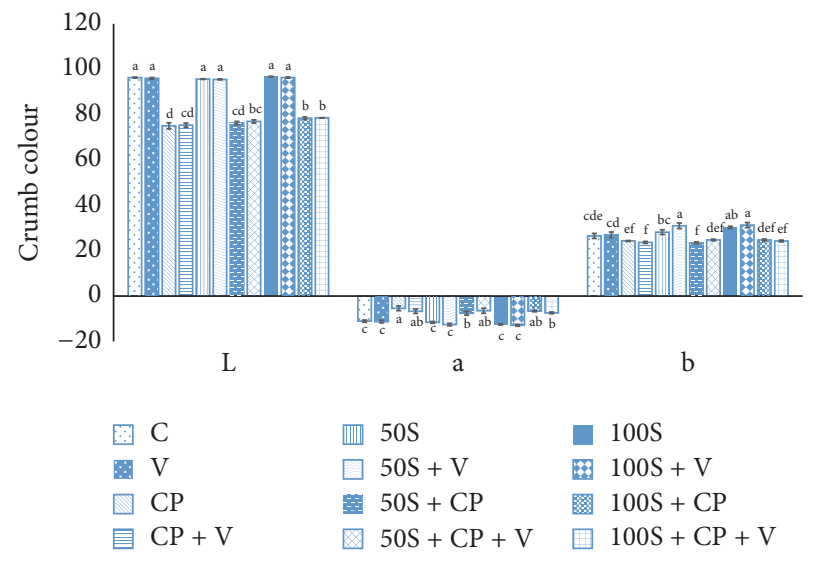

FIGURE 3: Effect of stevianna without/with cocoa powder and/or vanilla on the crumb colour of muffin. Control (C); vanilla (V); cocoa powder $(\mathrm{CP})$; cocoa + vanilla $(\mathrm{CP}+\mathrm{V}) ; 50 \%$ stevianna $(50 \mathrm{~S})$; $50 \%$ stevianna + vanilla $(50 \mathrm{~S}+\mathrm{V}) ; 50 \%$ stevianna + cocoa $(50 \mathrm{~S}+$ $\mathrm{CP}) ; 50 \%$ stevianna + cocoa + vanilla $(50 \mathrm{~S}+\mathrm{CP}+\mathrm{V}) ; 100 \%$ stevianna (100S); $100 \%$ stevianna + vanilla $(100 \mathrm{~S}+\mathrm{V}) ; 100 \%$ stevianna + cocoa $(100 \mathrm{~S}+\mathrm{CP}) ; 100 \%$ stevianna + cocoa + vanilla $(100 \mathrm{~S}+\mathrm{CP}+\mathrm{V})$.

in keeping with the findings of Martínez-Cervera et al. [27], which showed the addition of erythritol in muffins appeared not to influence the crust colour. The addition of vanilla also failed to change the colour of the muffin crust. Within the group with cocoa powder, crust $L^{*}, a^{*}$, and $b^{*}$ values were not significantly different for $0 \%, 50 \%$, and $100 \%$ stevianna with or without vanilla muffins (Figure 2).

In the group without cocoa power (Table 4), the stevianna containing samples had a $\Delta E^{*}>3$ compared to the control samples and were appreciably different by the human eye. The crust $\Delta E^{*}$ values of muffins with cocoa powder were notably higher than those of the control muffin (Table 4). The dark colour of cocoa powder used in this study influenced the overall colour of the muffins. Akesowan [19] showed a similar result in that the inclusion of cocoa powder affected the crust colour of the muffins. No significant differences were found in crust $\Delta E^{*}$ due to the use of stevianna in the group with cocoa powder. The results indicated that the cocoa powder diminished the crust colour change from stevianna. 


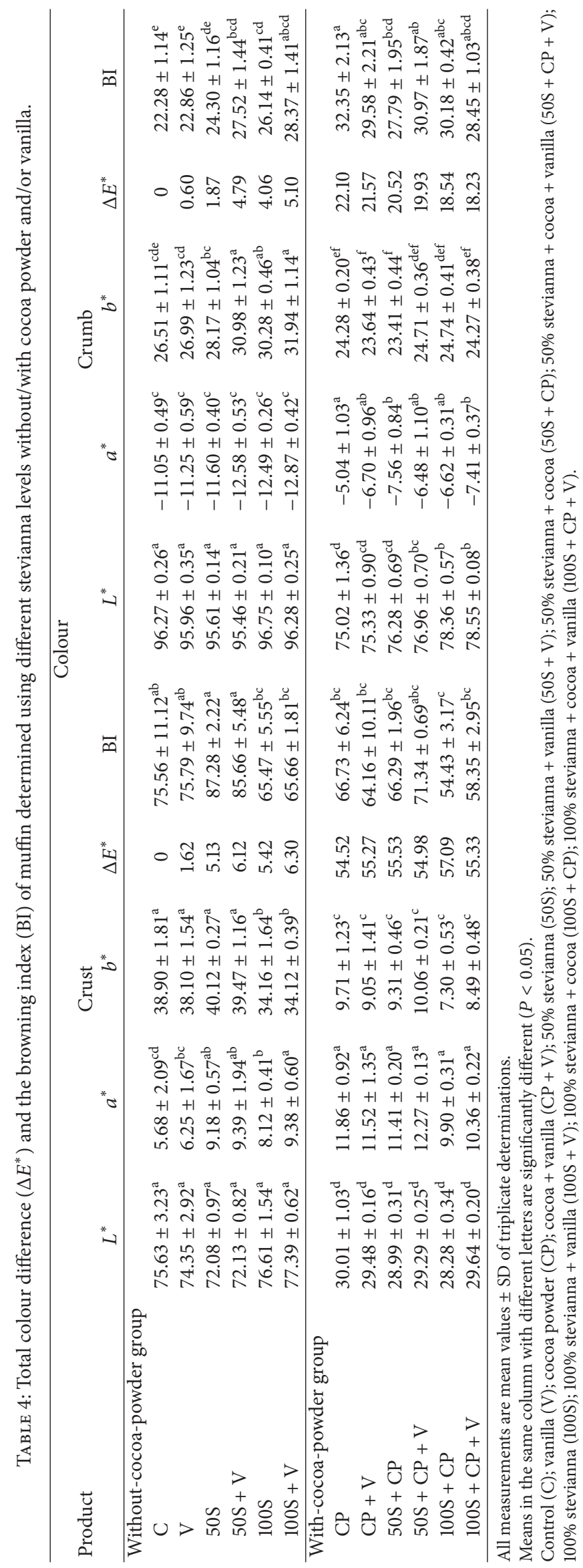


3.1.2. Crumb Colour. For the group without cocoa powder, Figure 3 presents $b^{*}$ values which indicate greater yellowness $(P<0.05)$ of the crumb of 50 and $100 \%$ stevianna with vanilla muffin, but the measured $L^{*}$ and $a^{*}$ values of colour did not show any significant differences.

The crumb $\Delta E^{*}$ values for $100 \%$ stevianna samples without cocoa powder were in excess of 3 units; however these values were lower than the crust $\Delta E^{*}$ values (Table 4). The difference between the crumb and crust colour was due to the fact that the crumb temperature does not get as high as the crust temperatures and therefore caramelization reaction does not occur in the crumb [28]. Within group containing cocoa powder, as the level of stevianna increased, the crumb $\Delta E^{*}$ value showed a decreasing trend, indicating a slightly lighter crumb was obtained as a result of the stevianna substitute. $a^{*}$ values and $b^{*}$ values from the muffin crumb indicated that both the red and yellow colour did not change significantly due to different amounts of stevianna with cocoa powder and/or vanilla. However, the lightness of muffin crumb was affected $(P<0.05)$ by the $100 \%$ stevianna replacement in muffins with cocoa powder (Figure 3). Lin et al. [16] reported that the addition of erythritol caused $L^{*}$ values to increase in the crumb colour.

3.1.3. Browning Index. BI is presented in Table 4. The BI is an appropriate index for investigating the colour differences in stevianna muffins due to the brown colour observed after the cocoa powder addition (Table 4). Overall, in muffins containing cocoa powder, colour changes observed due to the different stevianna levels were less intense in the crust than in the crumb. This is because the crust colour is affected mainly by Maillard and caramelization reactions, while the crumb colour depends to a higher extent on raw materials [29]. The addition of cocoa powder resulted in significantly higher values $(P<0.05)$ of BI than the control sample.

3.2. Textural Properties. Firmness and springiness are the main textural properties of a muffin, which are related to quality. Textural analysis provides an accurate estimation of firmness through measurement of the maximum force during the 1st compression. Springiness provides information about the sample's recovery from deformation, with springiness referring to the recovery between 2 compressions [30].

With respect to sucrose replacement, the $100 \%$ stevianna $(100 S)$ muffin showed firmness values significantly higher $(P<0.05)$ than the control (Figure 4), while springiness decreased when $100 \%$ of the sucrose was replaced by stevianna (Figure 5). Overall, these results indicate that the addition of $100 \%$ stevianna as a sugar replacer in muffins gave harder and more crumbly muffins with a more compact, less aerated crumb.

These results could be related to the ability of sugar to retard the gelatinization of starch, which has been found to lead to a softening effect on bakery products [31]. Therefore, removing sugar from the muffin was responsible for the effect on muffin firmness and springiness. Similarly, MartínezCervera et al. [27] showed significantly higher firmness values in the sucrose-free muffins when using $100 \%$ sucrose replacement with erythritol than in control muffins. Akesowan [19]

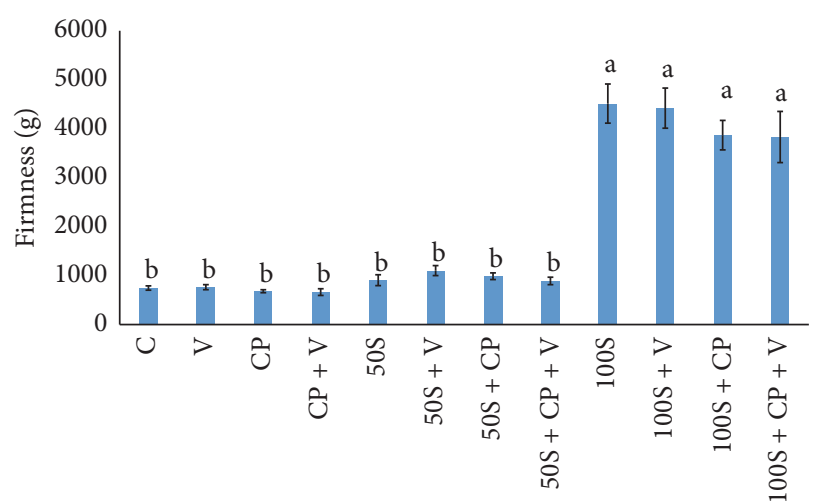

FIgURE 4: Firmness values for muffins containing two levels of stevianna as sugar replacer with or without cocoa powder and vanilla. Control (C); vanilla (V); cocoa powder (CP); cocoa + vanilla $(\mathrm{CP}+\mathrm{V}) ; 50 \%$ stevianna $(50 \mathrm{~S}) ; 50 \%$ stevianna + vanilla $(50 \mathrm{~S}+\mathrm{V})$; $50 \%$ stevianna + cocoa $(50 \mathrm{~S}+\mathrm{CP}) ; 50 \%$ stevianna + cocoa + vanilla $(50 \mathrm{~S}+\mathrm{CP}+\mathrm{V}) ; 100 \%$ stevianna $(100 \mathrm{~S}) ; 100 \%$ stevianna + vanilla $(100 \mathrm{~S}+\mathrm{V}) ; 100 \%$ stevianna + cocoa $(100 \mathrm{~S}+\mathrm{CP}) ; 100 \%$ stevianna + cocoa + vanilla $(100 \mathrm{~S}+\mathrm{CP}+\mathrm{V})$.

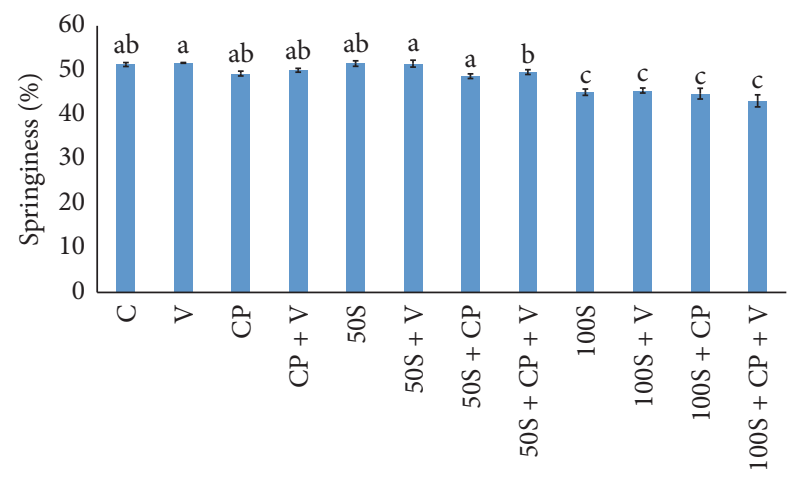

Figure 5: Springiness values for muffins made from two levels of stevianna as sugar replacer with or without cocoa powder and vanilla. Control (C); vanilla (V); cocoa powder (CP); cocoa + vanilla $(\mathrm{CP}+\mathrm{V}) ; 50 \%$ stevianna $(50 \mathrm{~S}) ; 50 \%$ stevianna + vanilla $(50 \mathrm{~S}+\mathrm{V})$; $50 \%$ stevianna + cocoa $(50 \mathrm{~S}+\mathrm{CP}) ; 50 \%$ stevianna + cocoa + vanilla $(50 \mathrm{~S}+\mathrm{CP}+\mathrm{V}) ; 100 \%$ stevianna $(100 \mathrm{~S}) ; 100 \%$ stevianna + vanilla $(100 \mathrm{~S}+\mathrm{V}) ; 100 \%$ stevianna + cocoa $(100 \mathrm{~S}+\mathrm{CP}) ; 100 \%$ stevianna + cocoa + vanilla $(100 \mathrm{~S}+\mathrm{CP}+\mathrm{V})$.

also found an increase in the firmness of sugar-free chiffon cakes prepared with an erythritol-sucralose mixture.

No significant differences in firmness or springiness were found at $50 \%$ sucrose replacement with stevianna compared with the control sample (Figures 4 and 5). The results were consistent with previous research [21]. When only $50 \%$ of sugar is removed, there is still sufficient sugar present to support better texture.

3.3. Sensory Evaluation. In order to assess the acceptability of the muffins formulations, sensory evaluation was carried out. The transformed data of crust colour, mouthfeel, texture, sweetness, appearance, and overall liking of the low-sugar muffins with/without cocoa powder and/or vanilla are presented in Table 5. 
TABLE 5: Sensory evaluation of half-sugar/sugar-free muffins in comparison with the control muffin which was taken as relative value and processed factor values for each experimental sample.

\begin{tabular}{|c|c|c|c|c|c|c|}
\hline Type & Colour & Mouthfeel & Sweetness & Texture & Visually & Overall liking \\
\hline $\mathrm{V}$ & $-0.82^{b}$ & $-0.18^{\text {cd }}$ & $0.08^{\mathrm{a}}$ & $-0.35^{b}$ & $-0.31^{\mathrm{ab}}$ & $-0.24^{\mathrm{ab}}$ \\
\hline $\mathrm{CP}$ & $4.14^{\mathrm{a}}$ & $-0.24^{\mathrm{cd}}$ & $-0.63^{\mathrm{a}}$ & $-0.57^{\mathrm{b}}$ & $0.39^{\mathrm{a}}$ & $-0.23^{\mathrm{ab}}$ \\
\hline $\mathrm{CP}+\mathrm{V}$ & $4.09^{\mathrm{a}}$ & $-0.4^{\mathrm{d}}$ & $-0.61^{\mathrm{a}}$ & $-0.88^{\mathrm{b}}$ & $0.31^{\mathrm{a}}$ & $-0.50^{\mathrm{a}}$ \\
\hline $50 \mathrm{~S}$ & $0.38^{\mathrm{b}}$ & $-0.42^{\mathrm{d}}$ & $-0.03^{\mathrm{a}}$ & $-1.43^{\mathrm{b}}$ & $-0.28^{\mathrm{a}}$ & $0.02^{\mathrm{a}}$ \\
\hline $50 S+V$ & $0.3^{\mathrm{b}}$ & $-0.46^{\mathrm{d}}$ & $0.61^{\mathrm{a}}$ & $-1.09^{\mathrm{b}}$ & $0.03^{\mathrm{a}}$ & $-0.18^{\mathrm{a}}$ \\
\hline $50 S+C P$ & $4.99^{\mathrm{a}}$ & $0.18^{\mathrm{bcd}}$ & $-0.82^{\mathrm{a}}$ & $-1.07^{\mathrm{b}}$ & $0.5^{\mathrm{a}}$ & $-1.1^{\mathrm{abc}}$ \\
\hline $50 S+C P+V$ & $5.15^{\mathrm{a}}$ & $0.4^{\mathrm{abcd}}$ & $-0.96^{\mathrm{a}}$ & $-1.14^{\mathrm{b}}$ & $0.59^{\mathrm{a}}$ & $-0.93^{\mathrm{abc}}$ \\
\hline $100 \mathrm{~S}$ & $-1.01^{\mathrm{b}}$ & $1.74^{\mathrm{abc}}$ & $0.39^{\mathrm{a}}$ & $2.63^{\mathrm{a}}$ & $-2.66^{\mathrm{c}}$ & $-2.46^{\mathrm{c}}$ \\
\hline $100 S+V$ & $0.34^{\mathrm{b}}$ & $1.49^{\mathrm{abcd}}$ & $-0.41^{\mathrm{a}}$ & $2.81^{\mathrm{a}}$ & $-3.06^{\mathrm{c}}$ & $-2.75^{\mathrm{c}}$ \\
\hline $100 S+C P$ & $4.36^{\mathrm{a}}$ & $2.31^{\mathrm{a}}$ & $-1.14^{\mathrm{a}}$ & $3.12^{\mathrm{a}}$ & $-2.59^{b c}$ & $-2.52^{\mathrm{c}}$ \\
\hline $100 S+C P+V$ & $4.21^{\mathrm{a}}$ & $1.92^{\mathrm{ab}}$ & $-1.19^{\mathrm{a}}$ & $2.71^{\mathrm{a}}$ & $-2.63^{\mathrm{c}}$ & $-2.41^{b c}$ \\
\hline
\end{tabular}

Mean values with the same superscript letter within the same column are not significantly different at $P<0.05$.

3.3.1. Crust Colour. Muffin samples containing stevianna at levels $50 \%$ and $100 \%$ with or without vanilla were judged not to be significantly different in crust colour to the control, because the properties of stevianna do not affect the crust colour of muffin. This result was consistent with the instrumental analysis. Understandably, muffins containing cocoa powder showed significantly darker crust colour $(P<0.05)$. Panellist ratings agreed with $\Delta E^{*}$ values, which indicated that the crust of muffins became darker when the cocoa powder was added. Martínez-Cervera et al. [24] evaluated the effects of cocoa addition on sensory characteristics of crust colour, and samples were perceived to have a stronger chocolate colour than the control muffin. Generally, the sensory evaluation of crust colour followed the instrumental measurements, while the panellists did not distinguish the minor differences detected by the colorimeter.

3.3.2. Mouthfeel and Texture. The sensory evaluation of texture was in good agreement with the instrumental measurement of firmness. The muffins with $50 \%$ sugar replacement were evaluated as not significantly different to the control muffin in terms of texture and mouthfeel. At 100\% stevianna replacement levels, all muffins, with/without cocoa powder and/or vanilla, were perceived as being significantly harder and having a drier mouthfeel $(P<0.05)$ when compared to control. The trend in mouthfeel is counter to the moisture content of the muffins (data not shown) and may reflect the humectant effect of the erythritol holding water content. Instrumental texture profile analysis also indicated that higher levels of stevianna had a negative effect on the texture quality of the muffin. Several authors have obtained similar results in other lowered sugar products. For instance, Akesowan [19] included differing levels of erythritol-sucralose in cake formulations and found that with increasing content of erythritol-sucralose the cake texture became harder than the control. Martínez-Cervera et al. [32] also found significantly lower texture scores in low-sucrose muffins prepared with sucralose than controls.

3.3.3. Appearance. The $100 \%$ stevianna muffins with/without cocoa powder and/or vanilla were significantly $(P<0.05)$ less appealing than those made with $0 \%$ and $50 \%$ stevianna, showing that when higher levels of stevianna were used muffins lost visual appeal. It is likely that the flat upper surface of the muffins resulted in the lowest panellist visual ratings for 100S muffins.

3.3.4. Sweetness. Compared with control samples, there was no significant difference in panellist ratings for sweetness of the sugar-free or sugar-reduced muffins without cocoa powder. It appears that the amount of stevianna added to the formulations is theoretically equal to the amount of sucrose in the basic formulation of the muffins, since stevianna product is 1 time sweeter than sucrose. Table 5 illustrates that the use of increasing amounts of stevianna with cocoa powder resulted in a slightly lower perceived sweetness when compared against other muffin samples; however this was not significant. The bitterness of cocoa powder could have affected the perceived sweetness of the muffin. The result is in agreement with previous findings which showed that sugar replacement by different polyols in sponge cakes did not affect the overall sweetness of the product when sucrose was replaced by xylitol, sorbitol, and maltitol [33].

3.3.5. Overall Liking. The panellists' ratings for overall liking tended to decrease with increasing sucrose replacement level, following the trend observed for the other sensory parameters. Those muffins prepared with $50 \%$ stevianna were not significantly different to the control muffin and were more highly appreciated by panellists than the $100 \%$ sugar-free muffins. The lowest overall liking ratings were obtained when $100 \%$ stevianna was in the muffin products; these muffins had a poor appearance, hard texture, and dry mouthfeel. The sensory result shows the poor overall liking ratings of $100 \mathrm{~S}$ muffin products were mainly due to the effects of appearance, mouthfeel, and texture. Struck et al. [34] reported similar observations, illustrating that partial sucrose replacement by rebaudioside $\mathrm{A}$ resulted in products having similar overall liking to the control muffin used.

The sample with $50 \%$ of the sugar replaced by the stevianna had similar visual appearance, colour, texture, mouthfeel, and overall liking to the control muffin. 
TABLE 6: Panellist descriptors and frequency of aftertaste in muffin products.

\begin{tabular}{lcc}
\hline Aftertaste & Descriptors & Total count (number of times) \\
\hline No-aftertaste & NA & 475 \\
Bitterness & Chocolate flavour, dark chocolate, bitter chocolate taste, cocoa taste & 37 \\
Other aftertastes & Artificial sweet, egg, baking soda, sour, flour taste, not good aftertaste, little bitter, plant & 48 \\
\hline
\end{tabular}

3.3.6. Aftertaste. In a preliminary study with muffins containing stevianna, a bitter aftertaste was noted so the added flavoured ingredients were tested for their masking effect on this negative taste. Cocoa powder and vanilla were chosen as classic muffin flavour with a natural bitterness and sweetness, respectively. Table 6 presents the aftertaste results obtained by analysing the descriptions given by panellists over the three sensory analysis sessions conducted for all types of muffin sample. It can be seen that $8.6 \%$ of panellists noted some aftertaste and used words such as "little bitterness," "artificial sweetness," "sour," and "flour taste," in muffins without cocoa powder. According to the panellist descriptions, stevianna substitution in control muffins resulted in the occurrence of a little bitterness which is attributed to the inherent bitterness of steviol glycosides [9]. Of the total number of participants, $6.6 \%$ of the panellists expressed an aftertaste of bitterness that was associated with the cocoa powder containing muffins and hence may be related to the flavour of cocoa. When a nominal logistic regression was fitted to data it showed the stevianna muffins had a bitter response, with the main bitterness derived from the presence of cocoa powder $(P<$ $0.05)$. In this group of panellists, the overall liking improved when vanilla was added to the cocoa formulation (Table 6). This implied that the addition of cocoa powder could mask the stevianna bitterness in terms of taste and that the addition of vanilla enhanced the flavour in muffins. This observation is similar to results obtained by Hui and Nip [3] and BelščakCvitanović et al. [35] who recorded that the presence of vanilla in cereal products serves to enhance the sweetness of products through both flavour and odour receptors.

3.4. Principal Component Analysis. In order to illustrate the differences between product types based on individual panellist perceptions of sensation, principal component analysis (PCA) was utilized. The group average plot (Figure 6) shows that all the muffin samples were separated, and the replicates of each muffin analysis were close to each other indicating that the panel evaluation was consistent [36]. PCA extracted two components that explained $96.5 \%$ of the variation. The first component which segregated the samples based on sugar replacement and addition of cocoa powder/vanilla was positively correlated with the attributes of appearance, overall liking, and sweetness and negatively correlated with mouthfeel and texture (explaining 64.5\% of the variation). The second component, which explained $32.0 \%$ of the variation, was mainly positively correlated with crust colour.

Consequently, the sensory characteristics of all the samples are mainly explained by the positive side of principal component 1 (PC1). These samples (V, CP, CP + V, 50S, 50S + $\mathrm{V}, 50 \mathrm{~S}+\mathrm{CP}$, and $50 \mathrm{~S}+\mathrm{CP}+\mathrm{V})$ possessed the highest rating

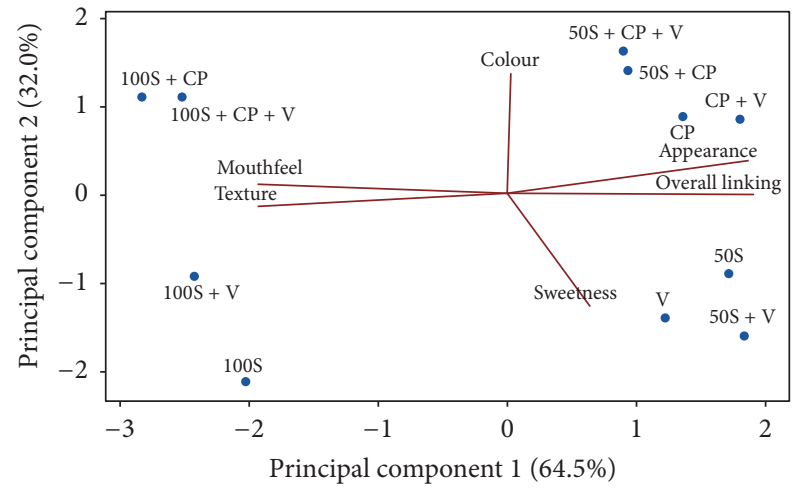

FIgURE 6: Principal component analysis of muffin attributes. Control $(\mathrm{C})$; vanilla $(\mathrm{V})$; cocoa powder $(\mathrm{CP})$; cocoa + vanilla $(\mathrm{CP}+$ $\mathrm{V}) ; 50 \%$ stevianna (50S); $50 \%$ stevianna + vanilla $(50 \mathrm{~S}+\mathrm{V}) ; 50 \%$ stevianna + cocoa $(50 \mathrm{~S}+\mathrm{CP}) ; 50 \%$ stevianna + cocoa + vanilla $(50 \mathrm{~S}$ + CP + V); $100 \%$ stevianna (100S); $100 \%$ stevianna + vanilla (100S + V); $100 \%$ stevianna + cocoa $(100 \mathrm{~S}+\mathrm{CP}) ; 100 \%$ stevianna + cocoa + vanilla $(100 \mathrm{~S}+\mathrm{CP}+\mathrm{V})$.

for appearance, overall liking, and sweetness. Muffins made by the addition of $100 \%$ stevianna showed negative coordinates along $\mathrm{PCl}$ and were mainly characterized by attributes mouthfeel and texture as an index of the textural properties of the sample. The main descriptor which was associated with PC2 is crust colour, when with-cocoa-powder samples were more distant from the without-cocoa-powder samples corresponding to differentiations in chocolate colour.

Therefore, the results of this study indicate the potential of using stevianna to completely replace sugar when combined with cocoa powder and vanilla to achieve the desired sweetness of a food product. However, further optimizing is required to obtain muffins with satisfactory textural properties and mouthfeel and an appealing appearance that would satisfy consumer preference.

\section{Conclusions}

The results of this investigation show that an encouraging option and novel formulation of muffin production with stevianna and cocoa powder/vanilla were developed. Muffins formulated with partial replacement of sucrose with up to $50 \%$ stevianna had sensory and texture characteristics comparable with muffins prepared with $100 \%$ sucrose. When $100 \%$ stevianna replaced sugar in the sugar-free formulation some negative sensory ratings were observed, namely, bitter aftertaste, poor appearance, hard texture, and dry mouthfeel leading, to reduced acceptability. Cocoa powder and vanilla were added to the formulation with stevianna in an attempt to mask any bitter aftertaste arising from the stevianna and to 
enhance product flavour. While this was successful in some sensory properties, $100 \%$ stevianna muffins possessed poor physical qualities and were associated with texture failure. Further work is required to conduct an in vitro digestion analysis to assess whether the sugar replacement of the muffins can lead to a reduction in the predicted glycaemic response from the muffin material.

\section{Competing Interests}

The authors declare that there is no conflict of interests regarding the publication of this paper.

\section{Acknowledgments}

The authors wish to thank Miriam Hodge for assistance with statistical analyses.

\section{References}

[1] F. Branca, H. Nikogosian, and T. Lobstein, Challenge of Obesity in the WHO European Region and the Strategies for Response, EURO Nonserial Publication (CH: World Health Organization Regional Office for Europe), 2007.

[2] H. M. Devereux, G. P. Jones, L. McCormack, and W. C. Hunter, "Consumer acceptability of low fat foods containing inulin and oligofructose," Journal of Food Science, vol. 68, no. 5, pp. 18501854, 2003.

[3] Y.-H. Hui and W.-K. Nip, "Sweeteners," in Bakery Products: Science and Technology, W. Zhou and Y. H. Hui, Eds., pp. 137160, Wiley-Blackwell, Oxford, UK, 2006.

[4] A. M. Abdel-Salam, A. S. Ammar, and W. K. Galal, "Evaluation and properties of formulated low calories functional yoghurt cake. Vol 7. (2) 218-221," Journal of Food, Agriculture \& Environment, vol. 7, no. 2, pp. 218-221, 2009.

[5] A. Drewnowski, K. Nordensten, and J. Dwyer, "Replacing sugar and fat in cookies: impact on product quality and preference," Food Quality and Preference, vol. 9, no. 1-2, pp. 13-20, 1998.

[6] S. Edelstein, K. Smith, A. Worthington et al., "Comparisons of six new artificial sweetener gradation ratios with sucrose in conventional-method cupcakes resulting in best percentage substitution ratios," Journal of Culinary Science and Technology, vol. 5, no. 4, pp. 61-74, 2008.

[7] V. Psimouli and V. Oreopoulou, "The effect of alternative sweeteners on batter rheology and cake properties," Journal of the Science of Food and Agriculture, vol. 92, no. 1, pp. 99-105, 2012.

[8] S. Martínez-Cervera, A. Salvador, and T. Sanz, "Comparison of different polyols as total sucrose replacers in muffins: thermal, rheological, texture and acceptability properties," Food Hydrocolloids, vol. 35, pp. 1-8, 2014.

[9] M. C. Carakostas, L. L. Curry, A. C. Boileau, and D. J. Brusick, "Overview: the history, technical function and safety of rebaudioside A, a naturally occurring steviol glycoside, for use in food and beverages," Food and Chemical Toxicology, vol. 46, no. 7, pp. S1-S10, 2008.

[10] S. Struck, D. Jaros, C. S. Brennan, and H. Rohm, "Sugar replacement in sweetened bakery goods," International Journal of Food Science and Technology, vol. 49, no. 9, pp. 1963-1976, 2014.
[11] M. A. A. Gasmalla, R. Yang, and X. Hua, "Stevia rebaudiana Bertoni: an alternative sugar replacer and its application in food industry," Food Engineering Reviews, vol. 6, no. 4, pp. 150-162, 2014.

[12] J. M. Geuns, Stevia and Steviol Glycosides, Euprint Heverlee, 2010.

[13] J. Goosens and H. Roper, "Erythritol: a new sweetner," Food Science and Technology Today, vol. 8, pp. 144-149, 1994.

[14] D. Storey, A. Lee, F. Bornet, and F. Brouns, "Gastrointestinal tolerance of erythritol and xylitol ingested in a liquid," European Journal of Clinical Nutrition, vol. 61, no. 3, pp. 349-354, 2006.

[15] I. C. Munro, W. O. Bernt, J. F. Borzelleca et al., "Erythritol: An interpretive summary of biochemical, metabolic, toxicological and clinical data," Food and Chemical Toxicology, vol. 36, no. 12, pp. 1139-1174, 1998.

[16] S.-D. Lin, C.-F. Hwang, and C.-H. Yeh, "Physical and sensory characteristics of chiffon cake prepared with erythritol as replacement for sucrose," Journal of Food Science, vol. 68, no. 6, pp. 2107-2110, 2003.

[17] S. Zahn, A. Forker, L. Krügel, and H. Rohm, "Combined use of rebaudioside A and fibres for partial sucrose replacement in muffins," LWT_Food Science and Technology, vol. 50, no. 2, pp. 695-701, 2013.

[18] M. R. Baeva, I. N. Panchev, and V. V. Terzieva, "Comparative study of texture of normal and energy reduced sponge cakes," Nahrung - Food, vol. 44, no. 4, pp. 242-246, 2000.

[19] A. Akesowan, "Quality of reduced-fat chiffon cakes prepared with erythritol-sucralose as replacement for sugar," Pakistan Journal of Nutrition, vol. 8, no. 9, pp. 1383-1386, 2009.

[20] G. Manisha, C. Soumya, and D. Indrani, "Studies on interaction between stevioside, liquid sorbitol, hydrocolloids and emulsifiers for replacement of sugar in cakes," Food Hydrocolloids, vol. 29, no. 2, pp. 363-373, 2012.

[21] J. Gao, M. A. Brennan, S. L. Mason, and C. S. Brennan, "Effect of sugar replacement with stevianna and inulin on the texture and predictive glycaemic response of muffins," International Journal of Food Science and Technology, vol. 51, no. 9, pp. 1979-1987, 2016.

[22] M. Maskan, "Kinetics of colour change of kiwifruits during hot air and microwave drying," Journal of Food Engineering, vol. 48, no. 2, pp. 169-175, 2001.

[23] M. Bodart, R. de Peñaranda, A. Deneyer, and G. Flamant, "Photometry and colorimetry characterisation of materials in daylighting evaluation tools," Building and Environment, vol. 43, no. 12, pp. 2046-2058, 2008.

[24] S. Martínez-Cervera, A. Salvador, B. Muguerza, L. Moulay, and S. M. Fiszman, "Cocoa fibre and its application as a fat replacer in chocolate muffins," LWT-Food Science and Technology, vol. 44, no. 3, pp. 729-736, 2011.

[25] K. Warner and N. Michael Eskin, Methods to Access Quality and Stability of Oils and Fat-Containing Foods, AOCS Publishing, 1995.

[26] D. Petridis, P. Raizi, and C. Ritzoulis, "Influence of citrus fiber, rice bran and collagen on the texture and organoleptic properties of low-fat frankfurters," Journal of Food Processing and Preservation, vol. 38, no. 4, pp. 1759-1771, 2014.

[27] S. Martínez-Cervera, E. de la Hera, T. Sanz, M. Gómez, and A. Salvador, "Effect of using erythritol as a sucrose replacer in making spanish muffins incorporating xanthan gum," Food and Bioprocess Technology, vol. 5, no. 8, pp. 3203-3216, 2012. 
[28] D. M. Lebesi and C. Tzia, "Effect of the addition of different dietary fiber and edible cereal bran sources on the baking and sensory characteristics of cupcakes," Food and Bioprocess Technology, vol. 4, pp. 710-722, 2009.

[29] D. M. Lebesi and C. Tzia, "Use of endoxylanase treated cereal brans for development of dietary fiber enriched cakes," Innovative Food Science and Emerging Technologies, vol. 13, pp. 207-214, 2012.

[30] V. Psimouli and V. Oreopoulou, "The effect of fat replacers on batter and cake properties," Journal of Food Science, vol. 78, no. 10, pp. C1495-C1502, 2013.

[31] R. L. Barndt and R. N. Antenucci, "Fat and calorie-modified bakery products," in Low-Calorie Foods and Food Ingredients, R. Khan, Ed., pp. 106-137, Springer, Berlin, Germany, 1993.

[32] S. Martínez-Cervera, T. Sanz, A. Salvador, and S. M. Fiszman, "Rheological, textural and sensorial properties of low-sucrose muffins reformulated with sucralose/polydextrose," LWT - Food Science and Technology, vol. 45, no. 2, pp. 213-220, 2012.

[33] F. Ronda, M. Gómez, C. A. Blanco, and P. A. Caballero, "Effects of polyols and nondigestible oligosaccharides on the quality of sugar-free sponge cakes," Food Chemistry, vol. 90, no. 4, pp. 549-555, 2005.

[34] S. Struck, L. Gundel, S. Zahn, and H. Rohm, "Fiber enriched reduced sugar muffins made from iso-viscous batters," LWTFood Science and Technology, vol. 65, pp. 32-38, 2016.

[35] A. Belščak-Cvitanović, D. Komes, M. Dujmović et al., "Physical, bioactive and sensory quality parameters of reduced sugar chocolates formulated with natural sweeteners as sucrose alternatives," Food Chemistry, vol. 167, pp. 61-70, 2015.

[36] M. C. Díaz-Maroto, M. S. Pérez-Coello, and M. D. Cabezudo, "Effect of different drying methods on the volatile components of parsley (Petroselinum crispum L.)," European Food Research and Technology, vol. 215, no. 3, pp. 227-230, 2002. 

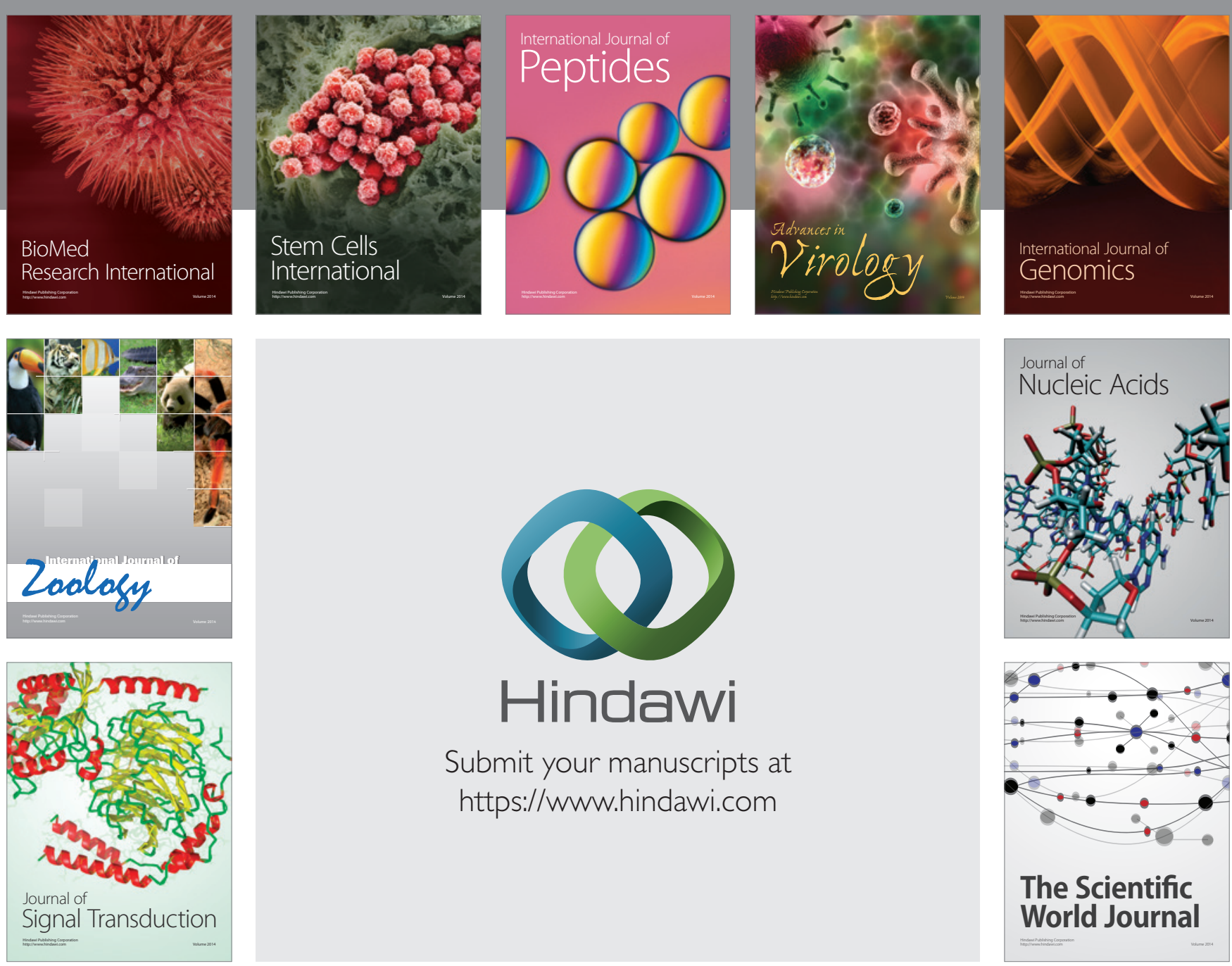

Submit your manuscripts at

https://www.hindawi.com
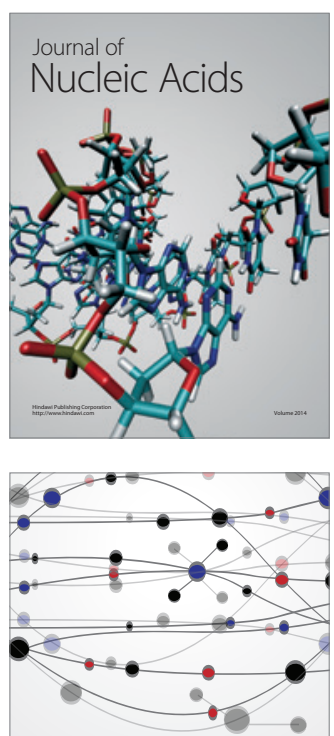

The Scientific World Journal
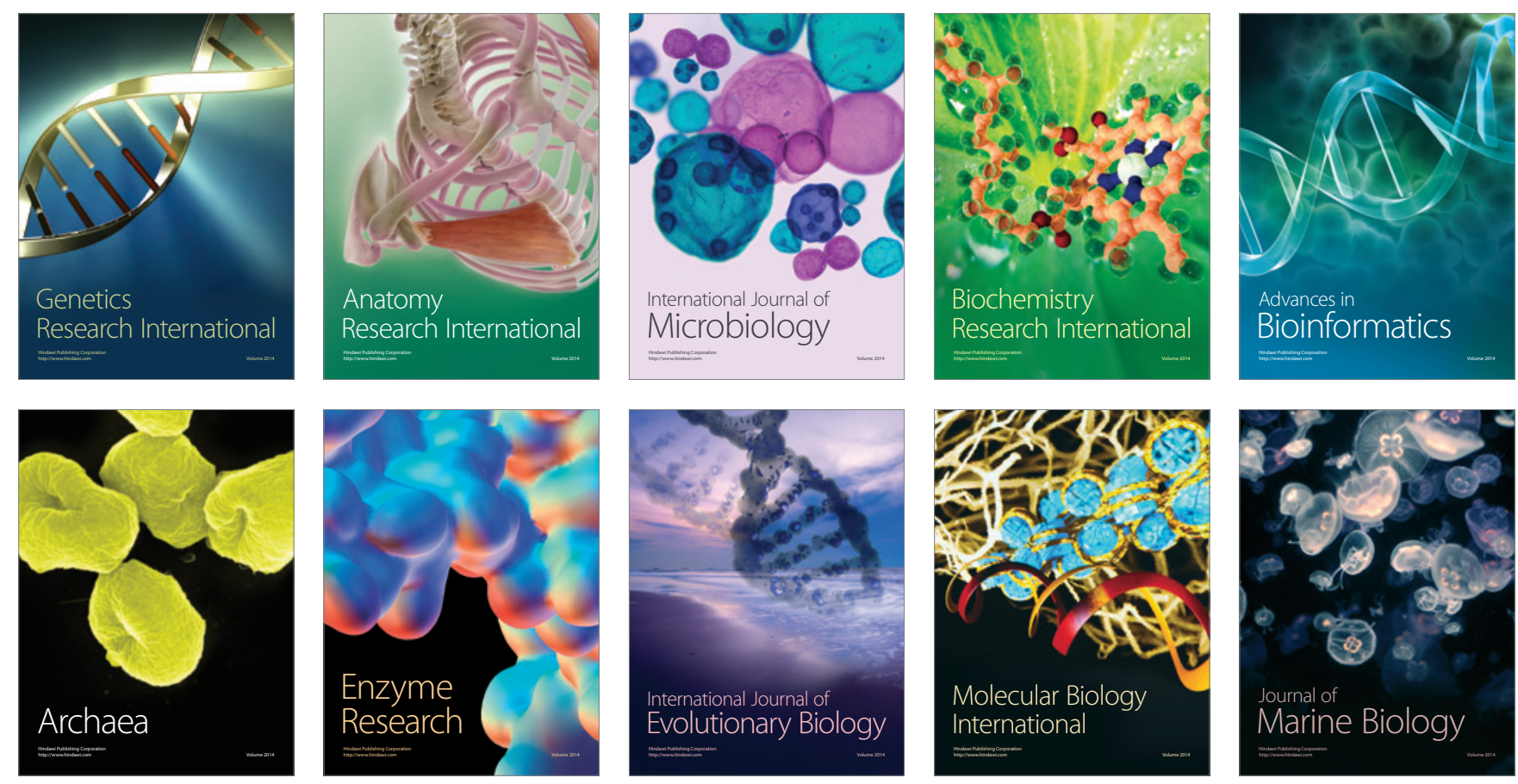